\title{
LONG SUN-EXPOSURES INFLUENCING HIGH SUB-CUTANEOUS SYNTHESIS OF VITAMIN-D3 MAY BE ASSOCIATED WITH EXACERBATION OF SYMPTOMS IN ALLERGIC-ASTHMA
}

\author{
L.G. D'Cruz 1,2,3,4, S.A. Husain', T. Wells², C. Morgan 3,5, P.J. Stanczyk², A. Satgunarajah', J. Kashir², \\ B.L. Calver ${ }^{2}$, L.M. Blayney², F.A. Lai ${ }^{2,6}$
}

\begin{abstract}
Objectives: Does excessive sun-exposure, non-use of sunscreen and/or high doses of vitamin-D3 supplements provoke exacerbation of asthma? Design: Clinical examinations, retrospective records-access and questionnaire surveys were distributed to a convenience sample of allergic-asthma patient $(n=183)$. Setting: Patients (19-89 years) attending the outpatient respiratory clinics at Maidstone Hospital were enrolled. Results: $90.3 \%$ of patients (total IgE levels $\geq 75 \mathrm{kU} / \mathrm{L} ; \mathrm{n}=103$ ) exposed to direct sunlight of $\geq 15$ minutes per day continuously for 6-7 days presented with wheeze $(\chi 2(1)=7.46 ; \mathrm{p}<0.05)$ compared to only $9.7 \%$ patients of similar atopy-status, presenting with wheeze if exposed to sunlight of $<15$ minutes per day for 6-7 days. 68.9\% patients (with IgE levels $\geq$ $75 \mathrm{kU} / \mathrm{L} ; \mathrm{n}=103$ ), non-users of sunscreen (SPF 30 and above), exposed to direct sunlight of $\geq 15$ minutes per day continuously for 6-7 days developed a wheeze, compared to fewer users of sunscreen $(9.7 \%, \mathrm{n}=103)$, exposed to the same duration of sunlight who developed asthma symptoms $(\mathrm{p}<0.05)$. Vitamin-D3 supplementation in asthma-patients with clinical signs of hypovitaminosis-D $(\mathrm{n}=21)$, produced symptoms of morning chest-tightness $(76.2 \%)$, allergic rhinitis $(61.9 \%)$ and wheeze (100\%), 2 weeks after initiation of treatment. Conclusions: Our results advocate direct sunlight exposure $<15$ minutes per day and use of sunscreen as a novel approach to preventing atopic-asthma symptoms in allergic-asthma patients.. Activated vitamin-D3 is well-recognised to shift the immune-balance towards Th2 predominance, favouring allergic asthma. These results suggest that limiting subcutaneous synthesis of vitamin-D3 in asthma patients and re-addressing dosage of vitamin-D3 supplementation is necessary may contribute to prevent exacerbation of symptoms.
\end{abstract}

Key words: Vitamin D, asthma, atopy, sunlight, Th1/Th2.

\section{Introduction}

With an increasingly elderly population, prone to falls, fractures and coupled with increased general bone fragility and/or fracture risk poses a significant challenge for health service provision. The biomechanical strength of bone declines when bone demineralization (or "bone-resorption") exceeds bone deposition or accrual. Conventional treatment to prevent the bone demineralization that occurs during osteoporosis or osteopenia is with calcium and vitamin-D supplementations, promoting consumption of a diet

1. Northern Ireland Centre for Stratified Medicine, University of Ulster, Northern Ireland; 2. College of Biomedical \& Life Sciences, School of Biosciences, Cardiff University, Cardiff, UK; 3. Respiratory Medicine Department, Maidstone \& Tunbridge Wells NHS Trust, Maidstone, Kent, UK; 4. Department of Cardiology and Cardiothoracic Surgery, University Hospital of Wales, Cardiff \& Vale NHS Trust, Cardiff University, Cardiff, UK; 5. Imperial College Respiratory Research Unit, St. Mary's Hospital, London, UK; 6. College of Medicine, Member of QU Health, Qatar University, Doha, Qatar

Corresponding Author: Dr. Leon Gerard D'Cruz, Northern Ireland Centre for Stratified Medicine, Altnagelvin Hospital, University of Ulster, Londonderry, Northern Ireland - BT47 6SB. Email: 1.dcruz@ulster.ac.uk; DCruzLG2@cardiff. ac.uk, Tel: $+44-(0) 2871675867$

rich in calcium and vitamin-D while encouraging sunlight-exposure to elevate subcutaneous synthesis of endogenous vitamin-D3.

Subcutaneous synthesis of previtamin-D3 is processed by the liver resulting in 25-hydroxyvitamin D (25D3), the main circulating "inactive" form of vitamin-D with a halflife of 15 days. 25D3 is converted to activated vitamin-D3; 1,25(OH)2-vitaminD3 (1,25D3) by 25-hydroxy-vitamin D-1- $\alpha$-hydroxylase (CYP27B1) in the kidneys $(1,2)$. The exposure levels necessary for optimal subcutaneous vitamin-D3 synthesis is dependent to a certain extent on skin pigmentation, darker skin colouring require longer exposures to fair skin since melanin absorbs UV-B radiation in the $290-320 \mathrm{~nm}$ range, melanin also serves as a light filter limiting the incident UV radiation available for the subcutaneous production of previtamin D3 (3). Clinical estimates of response to UV-light is determined using a phototyping scale by grading shades of skin colour with the Fitzpatrick scale (4)

Optimal levels of serum 1,25D3 are necessary to facilitate the absorption of calcium in the intestine via a transporter molecule called calcium-binding protein (CaBP) (also known as: calbindin-D) (5-8). Thus, 
vitamin-D3 is essential for normal duodenal absorption of dietary calcium, particularly in the elderly, although additional vitamin-D3-independent mechanisms for calcium absorption clearly exist (9).

In the clinical context, vitamin-D3 insufficiency is noted when serum levels of $25 \mathrm{D} 3$ is $<25 \mathrm{nmol} / \mathrm{L}$ whereas levels of $>50 \mathrm{nmol} / \mathrm{L}$ generally indicates sufficiency $(10$, 11). Vitamin-D3 supplementation is initiated when serum levels indicate hypovitaminosis-D or clinical judgement warrants it.

However, vitamin-D3 has another important role as it regulates the balance in T-helper cells in the immune system; in which T-helper 1 (Th1) cells are proinflammatory whereas Th2 cells exert a pro-surveillance/ anti-inflammatory influence (12-14).

1,25D3 favours the proliferation of Th2 type cells in culture (15), preferentially switching the immune-balance to Th2 predominance (16). This is potentially significant in atopic or allergic asthma in which the cytokines interleukin-4 (IL4) and IL13 drive a Th2- mediated quiescent yet surveillant immune response.

Asthma has traditionally been considered a disease of the young, but these preconceptions are changing, with emerging evidence that asthma may be significant in the elderly. In this age group asthma has often been underdiagnosed, leading to sub-optimal treatment (1719 ), and an increased risk of progression to critical stages, associated with elevated mortality -risk $(20,21)$.

Here lies the conundrum:, adequate levels of vitamin-D3 are necessary for optimal absorption of calcium (for healthy bone-maintenance) from diet, whereas high-levels of vitamin-D3 could potentially shift the immune balance to one of Th2-predominance, predisposing patients, especially the elderly, to an increased risk of an exacerbation of atopic asthma.

Thus, this study was conducted to determine the optimal levels of exposure to direct sunlight that would facilitate subcutaneous synthesis of vitamin-D3 without causing exacerbation of asthma symptoms that would be detrimental to lung function especially in elderly asthmatic patients.

\section{Methods}

\section{Selection of patients with asthma, clinical criteria}

Patients either referred for management of asthma from primary care or from previous admission to our respiratory specialist unit for asthma-exacerbations were approached for initial screening and possible inclusion into the study. Criteria for the diagnosis of asthma were as recommended by the 2016 British Thoracic Society (BTS)/ Scottish Intercollegiate Guidelines Network (SIGN) guidelines. Briefly, this included a documented history of recurrent coughing, wheeze, dyspnoea on exertion or at rest, improvement of symptoms with use of $\beta 2$ agonists and detailed clinical assessment (22).

Diagnosis of asthma was confirmed by previous demonstration of one of the following (i) reversibility of airflow obstruction (defined as improvement in FEV1 by $12 \%$ ) in 20 minutes following inhalation of a shortacting bronchodilator (eg. two puffs of 100 micrograms of Salbutamol) or (ii) $\geq 20 \%$ increase in diurnal variability in peak expiratory flow rate (PEFR) for 3 days in a week or over several weeks or (iii) $\geq 20 \%$ PEFR increase on standard asthma treatment (22).

\section{Recruitment and enrolment of participants to the study}

Patients ( $>18$ years of age) with a previously confirmed asthma diagnosis (by bronchodilator reversibility testing and/or by diurnal PEFR variability), clinical assessment and a confirmed history of atopy with raised allergenspecific immunoglobulin $\mathrm{E}$ (IgE) or positive radioallergosorbent test (RAST) to at least one aero-allergen (from documented history in case-notes) $(23,24)$ were approached for recruitment into the VIDAS (Vitamin D in atopy syndromes) study. Inclusion and exclusion criteria are summarised in table 1 . Written informed consent was obtained from each patient and documented in the allocated section at end of the questionnaire, following the explanation of the aims of the study by the members of the research team.

\section{Design of the questionnaire and study}

This was a cohort study on a convenience sample size $(n=183)$, recruited from a patient population demonstrating a history of atopy and asthma. The questionnaire (designed following extensive feedback from colleagues and patients) was distributed to all consenting inpatients and those attending follow-up outpatient respiratory clinics at Maidstone General Hospital (Maidstone, UK) between November 2015 and March 2016. The content of the questionnaire is akin to a standard clinical history-taking session, including an assessment of the vitamin-D status and their personal assessment of their nutritional and life-style choices.

The VIDAS questionnaire was designed to address the lack of suitable validated questionnaires to assess the effect that consumption of nutrition containing vitamin-D, vitamin-D supplementation, life-style choices and subcutaneous synthesis of vitamin-D can have on various respiratory symptoms in asthma.

\section{Evaluation of amount of sunlight exposure in patients}

Patients were asked via the VIDAS questionnaire, how much sunlight exposure they were exposed to, for the purpose of statistical analysis, the responses were 
collected in three groups, (i) less than 15 minutes of exposure, (ii) 15-30 minutes exposure or (iii) > 30 mins exposure.

Table 1

Inclusion and Exclusion criteria of the VIDAS study

\begin{tabular}{|c|c|}
\hline Inclusion criteria & Exclusion criteria \\
\hline $\begin{array}{l}\text { Patients with an established diagnosis } \\
\text { of asthma as defined by the guidelines } \\
\text { of the British Thoracic Society }(21,45)\end{array}$ & $\begin{array}{l}\text { Patients unable to give written } \\
\text { informed consent }\end{array}$ \\
\hline $\begin{array}{l}\text { Positive documented test results } \\
\text { in medical history to at least one } \\
\text { aeroallergen (house dust mites, pollens, } \\
\text { mould and animal dander) }\end{array}$ & $\begin{array}{l}\text { Documented history of significant } \\
\text { asthma exacerbation } 6 \text { weeks prior to } \\
\text { enrolment into the study }\end{array}$ \\
\hline $\begin{array}{l}\text { Positive documented medical history } \\
\text { of atopy }\end{array}$ & $\begin{array}{l}\text { Smoking history with } \geq 10 \text { pack years } \\
\text { or history of giving up smoking } \\
\text { (cigarettes, cigars, pipes, roll-ups) of } \\
<1 \text { year. }\end{array}$ \\
\hline Participants should be $\geq 18$ years of age & $\begin{array}{l}\text { Pregnancy either at enrolment or } \\
\text { during trial }\end{array}$ \\
\hline $\begin{array}{l}\text { Be able to give written informed } \\
\text { consent }\end{array}$ & $\begin{array}{l}\text { Patients undergoing } \\
\text { hyposensitisation therapy (allergen } \\
\text { immunotherapy) (46) or receiving } \\
\text { immunotherapy for asthma. }\end{array}$ \\
\hline \multirow{5}{*}{$\begin{array}{l}\text { Participants should be able to fill out } \\
\text { the questionnaire form in English or } \\
\text { if necessary, fill them out competently } \\
\text { with the aid of a suitable interpreter }\end{array}$} & $\begin{array}{l}\text { Patients with cardiac failure, ejection } \\
\text { fraction of }<30 \% \text { or wheeze due to } \\
\text { cardiac causes. }\end{array}$ \\
\hline & $\begin{array}{l}\text { Patients with cardiac failure, ejection } \\
\text { fraction of }<30 \% \text { or wheeze due to } \\
\text { cardiac causes. }\end{array}$ \\
\hline & $\begin{array}{l}\text { Patients with significant } \\
\text { electrocardiographic abnormalities }\end{array}$ \\
\hline & Patients with $\mathrm{BMI} \geq 30$ \\
\hline & $\begin{array}{l}\text { Patients with other diagnosis } \\
\text { of lung diseases such as COPD, } \\
\text { bronchiectasis, emphysema, cystic } \\
\text { fibrosis, sarcoidosis, interstitial lung } \\
\text { disease, pulmonary fibrosis or lung } \\
\text { cancer. }\end{array}$ \\
\hline
\end{tabular}

\section{Data of sunlight exposure and pollen counts}

Duration of sunlight between November 2015 and March 2016 for the geographical area surrounding Maidstone, Kent, UK was obtained from the webservice "Timeanddate.com" (Stavanger, Norway) using the "sunrise and sunset calculator" option (25). Data for the UK pollen and spore counts are maintained by the Midlands Asthma and Allergy Research Association, MAARA $(26,27)$.

\section{Ethics and institutional approvals}

The study was approved by the Maidstone and Tunbridge Wells (MTW) NHS Trust Research \& Development Department, the MTW-Trust Audit department and the Institutional Review Board of MTW NHS Trust. The study was carried out in accordance with GCP guidelines (28). All patients were treated appropriately with due care as per the requirements in the Declaration of Helsinki (29).

\section{Statistics}

Results were analysed using descriptive statistics. Chi square and the Fisher's exact test was used to test for independence and associations. All statistical analysis was carried out using SPSS ver 23 (IBM Corp), with $\mathrm{P}<0.05$ considered as statistically significant.

\section{Results}

250 patients were initially identified as being suitable for enrolment into the study; however a total of 183 patients finally consented to participating in the study over a staggered period of 4 months. Non-participants cited time as a factor, anxiousness whilst waiting for their outpatient appointments while others declined participation without stating reasons.

\section{Figure 1}

Distribution of gender and age of participants in the study

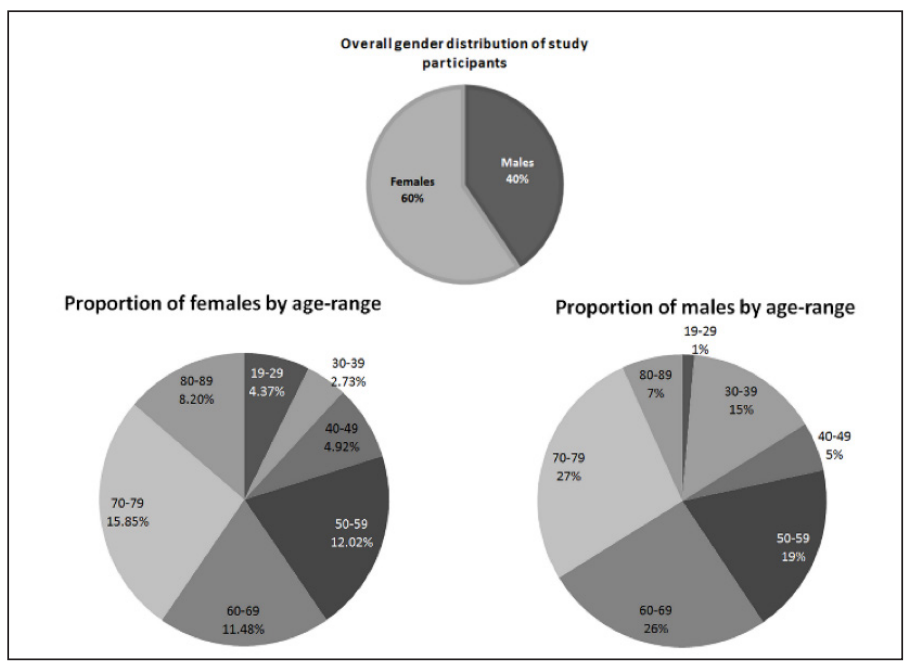

The study enrolled patients from a diverse age distribution, $47.6 \%$ of males and $79 \%$ of female participants were above the age of 50

Of the patients recruited, $40 \%$ were males and, $60 \%$ females, between the ages of 19 and 89 years, with the distribution of age ranges shown in Figure 1. It is important to note that, $47.6 \%$ of males and $79 \%$ of female participants were aged $\geq 50$. There was only one participant in the study from a non-Caucasian background, and although that patient (male) was of mixed Asian origin, he had fairly fair skin pigmentation.

All patients recruited to this study lived locally, within the catchment area of the hospital covering the south of West-Kent and the north of East-Sussex. Questionnaires were delivered by hand, to patients at their outpatients' appointment, forms were returned and checked by a member of the research staff, and thus the response rate was $100 \%$ for this study. 
The average duration of daily sunlight hours, in the area of Kent, during the months of November 2015 and March 2016 (the period of the study) was among the lowest in a year (winter to early spring in the United Kingdom), averaging between 8 and 11 hours per day (Figure 2).

\section{Figure 2}

Duration of daily sunlight observed in Kent, England Aug 2015-July-2016

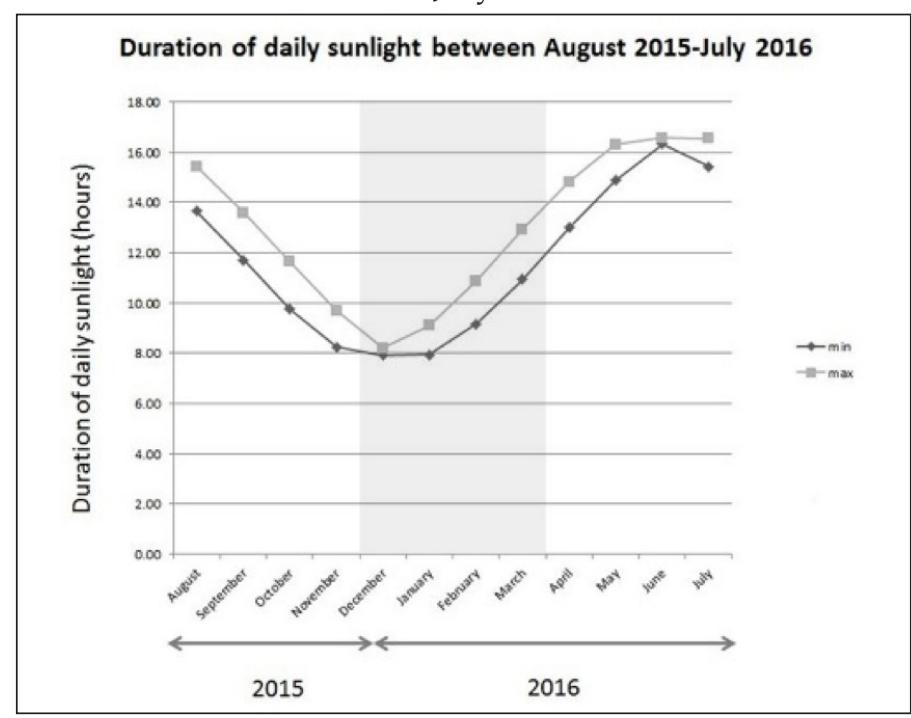

Results compiled for the town of Maidstone from the webservice - "Timeanddate. com", Stavanger, Norway (24).

Patients in this study with a clinically documented rise in specific IgE while demonstrating symptoms of wheeze and other symptoms of atopy were classified as having a "wheeze due to atopic causes". A total of 103 patients fell into this category, presenting with symptoms of atopic wheeze.

Exposure to direct sunlight of $\geq 15$ minutes per day for a continuous period of 6-7 days produced symptoms of atopic-wheeze in 93 patients $(90.3 \%, \mathrm{n}=103)$ compared to only $10(9.7 \%, \mathrm{n}=103)$ patients who developed atopic wheeze when exposed to direct sunlight of $<15$ minutes per day for a continuous period of 6-7 days (Figure 3a).

The Chi-square test was used to check if the development of atopic wheeze in asthma patients was independent of (not associated with) the duration of direct sunlight they were exposed to. However, the results indicated that a significant correlation was found, ( $\chi 2 \quad(1)=7.46 ; \mathrm{P}<0.05)$, the duration of direct sunlight that asthma patients were exposed to, in excess of 15 minutes per day continuously for 6-7 days, did influence the development of wheeze among asthma sufferers (Figure 3b).

There were fewer total number of patients who presented a wheeze from non-atopic causes in relation to the influence of the duration of exposure to direct sunlight ( $n=14$, Figure 3$)$. The Fisher's exact test was used to explore the association between non-atopic wheeze and the duration of direct sunlight exposure. A significant association between the duration of daily sunlight and the development of wheeze was noted, (Figure 3a; $\mathrm{P}=0.018$ ), indicating that these asthma patients, despite not having a rise in their total $\operatorname{IgE}$ levels, were significantly affected by sunlight exposure.

\section{Figure 3}

Development of wheeze after exposure to direct sunlight

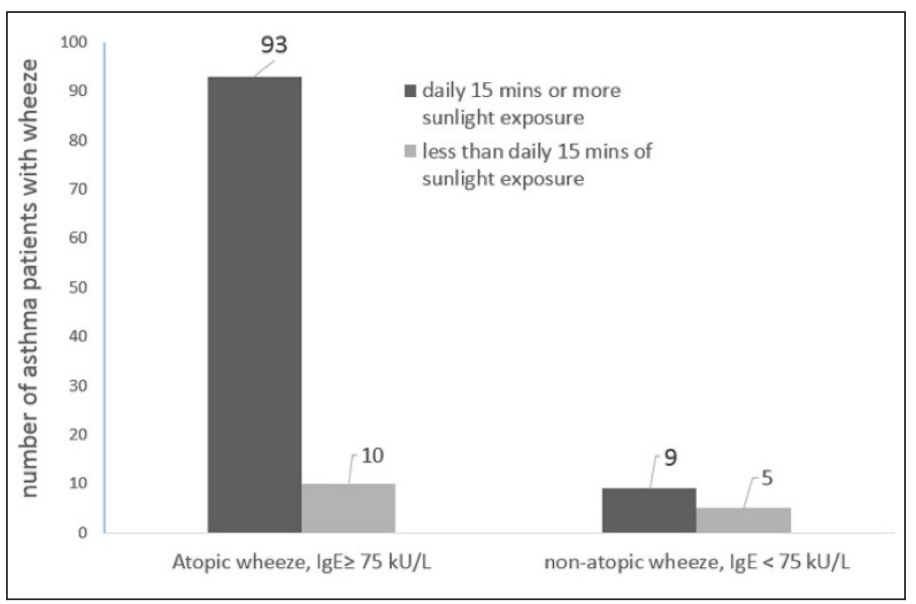

Serum total IgE levels were determined following presentation of wheeze. Wheeze associated with levels of total $\mathrm{IgE} \geq 75 \mathrm{kU} / \mathrm{L}$ was interpreted clinically as a positive atopic reaction to aeroallergens (house dust mites, pollens, mould or animal dander), common in allergic asthma whereas wheeze manifesting with low IgE levels (IgE $<75 \mathrm{kU} / \mathrm{L})$ is commonly associated with an infectious aetiology such as an upper respiratory infection. The number of asthma patients in each category is shown above the bars, there were a total of 103 patients who presented with wheeze due to atopic aetiology and 14 who presented with wheeze while also experiencing an upper respiratory tract infection with low total IgE levels (nonatopic wheeze).

The use of sunscreen among patients with asthma was investigated in this study, since subcutaneous vitamin-D3 synthesis would be reduced when the transmission of ultra-violet light to the skin is impeded. The majority of patients $(68.9 \%, \mathrm{n}=103)$ who presented with a wheeze "associated with atopic causes" (specific IgE levels $\geq 75$ $\mathrm{kU} / \mathrm{L}$ ), were not habitual sun-screen users, even when they ventured outdoors and were exposed to direct sunlight for approximately $\geq 15$ mins per day (Figure 4a).

We used the Chi-square test to explore if unimpeded subcutaneous synthesis of Vitamin-D3, by non-use of sunscreen, when exposed to sunlight $\geq 15$ mins per day, continuously for 6-7 days, has any effect on the development on wheeze.

The results showed a significant association between the non-use of sunscreen and the development of wheeze $(\chi 2(1)=10.098 ; P<0.05)$. This strongly suggested that unimpeded synthesis of subcutaneous vitamin-D3 from not using sunscreen, contributes to the development of wheeze in patients with serum levels of $\operatorname{IgE} \geq 75 \mathrm{kU} / \mathrm{L}$.

Figure $4 \mathrm{~b}$ shows the majority of patients that presented with wheeze without any "associated atopic causes" (specific IgE levels $<75 \mathrm{kU} / \mathrm{L}$ and no concomitant symptoms of atopy), were habitual users of sun-screen (SPF 30 and above) whenever they were exposed to direct 
sunlight $(73.33 \%, \mathrm{n}=15)$. The Fisher's exact test showed that a significant association exists, correlating the use of sun-screen and the development of wheeze $(\mathrm{P}=0.002)$ in patients with serum levels of $\operatorname{IgE}<75 \mathrm{kU} / \mathrm{L}$. These results are opposite to findings in figure $4 \mathrm{a}$, where the majority of atopic wheeze is seen among the non-users of sunscreen.

\section{Table 2}

Manifestation of asthma symptoms in patients treated with cholecalciferol (vitamin-D3) for low serum vitamin-D levels

Number of patients on treatment for clinically 21

determined low vitamin-D3 levels $(<30$

$\mathrm{nmol} / \mathrm{L}$ )

Manifestation of the following symptoms two weeks after taking vitamin-D3 supplements

Wheeze

$$
21(100 \%) ; \mathrm{n}=21
$$

Breathlessness and chest tightness on waking $16(76.2 \%) ; n=21$ in the morning

Symptoms of allergic rhinitis (sneezing, itchy $13(61.9 \%) ; \quad n=21$ eyes, watery eyes (epiphora), runny nose (rhinorrhea).

Patients treated for low vitamin-D levels reported the manifestation of mild symptoms of asthma presenting approximately two weeks after taking vitamin-D3 supplements.

\section{Figure 4}

The effect of using sun-screen (impeding the subcutaneous synthesis of vitamin-D3) on the development of wheeze when patients are exposed to direct sunlight for $\geq 15$ mins per day

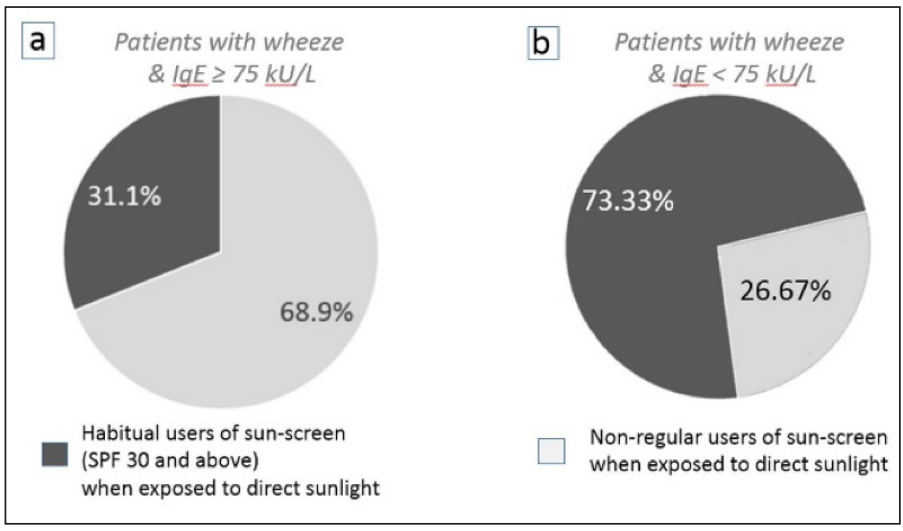

(a) $68.9 \%$ ( $n=103$ ) of patients who did not use sun-screen whenever being exposed to direct sunlight developed an atopic-wheeze $(\operatorname{IgE} \geq 75 \mathrm{kU} / \mathrm{L})$, compared to $31.1 \%$ of patients who were habitual users of sunscreen. (b) $73.33 \%$ of patients $(\mathrm{n}=15)$ who were habitual users of sunscreen and with IgE levels $<75 \mathrm{kU} / \mathrm{L}$ developed wheeze compared to $26.67 \%$ who did not use sun-screen.

In addition we observed the gradual clinical manifestation of mild symptoms commonly noted in an exacerbation of asthma (wheeze, chest tightness, dyspnoea) in patients who were being treated for low serum vitamin-D3 levels (25D3 concentration $<25$ $\mathrm{nmol} / \mathrm{L}$ ) or clinical signs of hypovitaminosis-D (high risk of fragile bones, osteoporosis or displaying clinical symptoms of osteomalacia, hypocalcaemia or Paget's disease) with 800 units of cholecalciferol (D3), once daily as recommended by the standard UK medical guidelines (30).

Two weeks after initiation of treatment, patients had reported mild symptoms of wheeze $(100 \%, n=21)$, dyspnoea and chest tightening on waking in the morning (76.2\%) and mild symptoms of allergic rhinitis; $61.9 \%$ (Table 2). As there was no clinical need for determination of serum total $\operatorname{IgE}$ levels for these patients, we do not know the serum-atopy status of these patients.

\section{Discussion}

Given the emerging evidence linking vitamin D3 with the progression of asthma, this study presents evidence in support of the hypothesis that elevated sunlight exposure exacerbates atopic wheeze, particularly in more mature patients.

The demographics of this study showed a preponderance of females to males $3: 2(\mathrm{P}=0.001)$ asthma patients. This is probably reflective of the population demographics in Kent, where $51 \%$ of the population was female (total population in Kent $=1.46$ million (31)). Our data also showed a shifting trend in the demographics of asthma, once regarded to be a disease of the young, where $79 \%$ of female asthma patients and just under half of all male asthma patients were over the age of 50 . Previously, inadequate knowledge about the disease, impairment of cognitive function, and non-optimal inhaler techniques all contributed to high mortality figures in the elderly asthma patient, however with better public educational resources, this trend is beginning to reverse.

We conducted our study during the winter-months, when sunlight-dependent vitamin-D synthesis in subcutaneous tissue is at its synthesis, would be lowest point in the calendar. Vitamin-D is usually synthesised as a result of the conversion of a precursor found under the skin following activation by ultra-violet radiation, UVB (wavelengths 270-300nm) from the sun (32). As a result, normal plasma calcium levels can be maintained if patients have sufficient sunlight exposure. It is widely recognised that approximately 15 minutes of exposure per day is sufficient to allow optimal subcutaneous synthesis of vitamin-D $(33,34)$. However, during the winter-months in countries situated north of the tropic of cancer, patients often record low-vitamin D levels due to a combination of unpleasant cold temperatures limiting their time outdoors and the reduced daylight hours with overcast skies (35). This study evaluated the responses of patients in three categories of sunexposure duration-times and correlated them with adverse respiratory symptoms. We hope to extend the study in future to examine other molecular markers that might be upregulated on subcutaneous light exposure 
such as calcidol (a Vitamin-D metabolite), p53 and c-Jun (transcription factors that are upregulated on UV exposure) and Toll-like receptor-9 (CD 289 ; an activator of the innate immune system) (36).

Epidemiological studies carried out previously have shown that Vitamin-D deficiency is significantly associated with the development of asthma and is a useful predictor for the risk of developing asthma in future (37). Epidemiological studies and experimental research demonstrating the association of Vitamin-D with asthma have been reviewed extensively elsewhere (38, 39), however few studies have addressed the duration of exposure of direct sunlight or the amount of vitamin-D either by prescription supplementation or diet and its impact on the exacerbation of symptoms in asthma. Our study explores the link between the duration of exposure to sunlight and the development of symptoms in asthma, particularly wheeze.

Wheeze can arise from various causes including "non-atopic causes" that can manifest during upperrespiratory-tract infections $(40,41)$ without the concomitant symptoms of atopy (eg. conjunctivitis, atopic dermatitis, immune-urticaria, allergic rhinitis) or without a rise in specific $\operatorname{IgE}$ or high total $\operatorname{IgE}(>75 \mathrm{kU} / \mathrm{L})$. $\mathrm{IgE}$ is the antibody class that is produced in response to allergic reactions, usually raised in exacerbations of symptoms in asthma which is why, omalizumab, the humanised antibody against the Fc receptor of $\operatorname{IgE}$, is such an effective treatment for patients with severe allergic asthma (42).

Our data indicate that exposure to direct sunlight for more than 15 minutes per day, continuously for nearly a week produced wheeze in a significant number of patients with the concomitant rise in IgE levels above $75 \mathrm{kU} / \mathrm{L}$ (Figure 3a). However, we also noted a similar sunlight-induced elevation in wheeze in patients who did not show a concomitant rise in IgE levels (Figure 3a). Thus, the development of wheeze was unlikely to be due to aeroallergens which would have triggered the increase in total serum IgE levels. As the duration of sunlight was the key variable in this observation, and since significantly less numbers of patients developed a wheeze if their daily exposure to direct sunlight was limited to less than 15 minutes per day. This supports the hypothesis that promoting the subcutaneous synthesis of vitamin-D3 may have been responsible.

If this is the case, then the use of sun-screen (SPF 30 and above) should theoretically improve the symptoms in asthma patients with atopic wheeze. We observed significant numbers of patients not using sun-screen developed wheeze with a rise in total IgE, whereas lower numbers of patients presented with wheeze among those that used sunscreen and had high IgE levels. Thus, in patients with high total IgE and wheeze, the use of sunscreen was beneficial, presumably limiting the amount of subcutaneous Vitamin-D synthesis. This is also a positive message to asthma sufferers since the use of adequate UV protection is preventative against the development of cutaneous squamous cell carcinoma (43).

However, it was confounding to note that significant numbers of patients with lower $\operatorname{IgE}$ levels $(<75 \mathrm{kU} / \mathrm{L})$ who habitually used sun-screen developed a wheeze. One possible interpretation for these results is that patients who had low circulating IgE levels and yet exhibiting symptoms of wheeze predominantly from inflammatory causes, were "Th1-switched" (Figure 4b). Patients fighting off an infection (with an immune balance switched to Th1) often present with acute wheezing through the production of pro-inflammatory mediators such as interleukin-1 (IL-1), IL-12, and IL-18, tumournecrosis factor (TNF), interferon gamma (IFN- $\gamma$ ), and granulocyte-macrophage colony stimulating factor), triggering a systemic neutrophilic response. This leads to pulmonary neutrophilia (44), with subsequent airway injury, remodelling, and small airway constriction contributing to wheeze

Throughout this study, the subcutaneous synthesis of vitamin-D3 from exposure to sunlight was indirectly implied since we were unable to directly measure the levels of vitamin-D3 in a cohort that were actively being exposed to sunlight. A rational approach to test the contribution of vitamin-D3 levels to the development of asthma symptoms would be to administer vitamin-D to patients, then observing the development of wheeze, however such a study would be ethically unjustifiable.

However, we observed the development of mild asthma symptoms in patients who had low serum vitamin-D levels ( $<25 \mathrm{nmol} / \mathrm{L})$ and/or had clinical signs of hypovitaminosis-D, thus having a clinical need for the administration of cholecalciferol (a vitamin-D3 supplement). 21 patients in this study were on treatment for hypovitaminosis-D and were treated with cholecalciferol. These patients had their asthma symptoms under good control at the outset (no wheeze, no chest-tightening or dyspnoea). We accept that the sample size for this observation was small, and therefore statistically under-powered, further observational trials probably involving multiple hospital sites is warranted.

As the asthma symptoms were mild, treatment for hypovitaminosis under senior clinician-care continued. The symptoms recorded for each of these patients were managed clinically with success by titrating their inhaler medication. These observations strongly suggest the role of vitamin-D3 in shifting the balance of the immune system towards a Th2 predominant balance, where symptoms of atopic wheeze predominate.

The threshold levels for hypovitaminosis-D are still under debate. However, the UK National Osteoporosis Society has applied threshold levels recommended by the US Institute of Medicine (IOM); serum levels of $25 \mathrm{D} 3>50 \mathrm{nmol} / \mathrm{L}$ should be recognised as vitamin-D "sufficient" $(45,46)$. The treatment of patients, presenting with clinical symptoms of hypovitaminosis-D, with supplements is a necessary measure. However, we propose that the dosage of vitamin-D supplementation needs to be readdressed for asthmatic patients. 


\section{Limitations of the study}

Unfortunately, selection bias cannot be ruled out in this study, despite the fact that home visits were offered to those who were unable to come to the research centre. Older and more infirm subjects did not participate in the study to the same extent as younger and healthier individuals. Consequently, the group of non-participants were comprised of relatively older, and probably frailer, subjects than those in the study population.

The study was conducted between the months of November and March, due to cold ambient conditions during this period, we expect that limited amount of skin would be exposed and therefore the application of sunscreen would be to less exposed areas than if the study were conducted in the summer-months. It was difficult to determine the amount of exposed areas, we hope to carry out a longer study incorporating assessment of all the months during the year, to address this limitation in this study.

This study exposes a very difficult and important conundrum; high vitamin-D is important for healthybones in a mid-elderly population prone to falls and fractures, but conversely high levels can worsen some lung-conditions. Recommending high-levels of vitamin-D supplementation or life-style choices that encourage high natural synthesis of vitamin-D in those at risk from falls and fractures can predispose an elderly asthmatic patient to frequent asthma exacerbations which can sometimes be fatal. Our study proposes that 15 minutes of direct sunlight exposure is sufficient to facilitate optimal subcutaneous synthesis of Vitamin-D3 that maintains bone-integrity among the vulnerable elderly population while keeping asthma symptoms at bay.

This study explores a number of areas in asthma, the importance of Vitamin-D and raises a number of questions that could be designed as separate studies for future research, particularly the appropriate dosage of vitamin-D supplementation in asthmatics. We aim to recruit larger numbers of asthma patients, in multiple hospital sites over a wider geographical area in order to refine and further elaborate the various findings noted in this study.

Acknowledgements: We acknowledge the contribution of the R\&D department at Maidstone Hospital, particularly Hazel Everest, Julie Knowles, Denise Day, research nurses Stephanie McKinley, Tracey Nolan, the Patien Research Ambassador- Frances Mossie and Nathan Boakes. We thank the Ken Lung Awareness Charity for assistance, support and critically assessing the questionnaires from a lay-perspective. We also would like to thank Prof. Zaheer Yousef, the HCRW All Wales clinical lead for Cardiovascular Research in Wales, for critical review of the manuscript.

Funding: LG D'Cruz was funded by the NIHR at Maidstone Hospital, The Sir Geraint Evans Wales Heart Research Institute, Cardiff, and currently funded by InvestNI in Northern Ireland. FAL was supported by the UK Science \& Innovation Network and The British Council.

Author Contributions: LG D'Cruz: Designed the study, recruited, clinically examined \& assessed the patients, carried out the statistical analysis and drafted the manuscript. SA Husain: clinically examined patients, involved in recruitment to study, reviewed manuscript. FA Lai: advised on design of study, reviewed manuscript. T Wells: reviewed manuscript and data. C Morgan \& A Satgunarajah :
Assisted in Clinical examination of patients and assisted in recruitment, reviewed manuscript; PJ Stanczyk, J Kashir, BL Calver, LM Blayney: Reviewed statistics, manuscript and data.

Disclosure: All authors in this manuscript declare that they have no conflicting interest

\section{References}

1. Lips P, Hosking D, Lippuner K, Norquist JM, Wehren L, Maalouf G, et al. The prevalence of vitamin D inadequacy amongst women with osteoporosis: an international epidemiological investigation. J Intern Med2006 Sep;260(3):24554

2. Nair R, Maseeh A. Vitamin D: The "sunshine" vitamin. J Pharmacol Pharmacother2012;3(2):118-26.

3. Norman AW. Sunlight, season, skin pigmentation, vitamin D, and 25-hydroxyvitamin D: integral components of the vitamin D endocrine system. Am J Clin Nutr1998 Jun;67(6):1108-10.

4. Fitzpatrick TB. The validity and practicality of sun-reactive skin types I through VI. Arch Dermatol1988 Jun;124(6):869-71.

5. Bronner F. Mechanisms and functional aspects of intestinal calcium absorption. J Exp Zool A Comp Exp Biol2003 Nov 1;300(1):47-52.

6. Buckley M, Bronner F. Calcium-binding protein biosynthesis in the rat: regulation by calcium and 1,25-dihydroxyvitamin D3. Arch Biochem Biophys1980 Jun;202(1):235-41.

7. Pansu D, Bellaton C, Roche C. [Intestinal absorption of calcium and its regulation. Tissue, membrane and molecular events]. Diabete Metab. 1984 May;10(2):106-20.

8. Christakos S, Gill R, Lee S, Li H. Molecular aspects of the calbindins. J Nutr1992 Mar;122(3 Suppl):678-82.

9. Wongdee K, Charoenphandhu N. Vitamin D-enhanced duodenal calcium transport. Vitam Horm 2015;98:407-40.

10. Spiro A, Buttriss JL. Vitamin D: An overview of vitamin D status and intake in Europe. Nutr Bull2014 Dec;39(4):322-50.

11. Lowe NM, Bhojani I. Special considerations for vitamin D in the south Asian population in the UK. Ther Adv Musculoskelet Dis2017 Jun;9(6):137-44.

12. Lemire JM. Immunomodulatory actions of 1,25-dihydroxyvitamin D3. J Steroid Biochem Mol Biol. 1995 Jun;53(1-6):599-602.

13. D'Ambrosio D, Cippitelli M, Cocciolo MG, Mazzeo D, Di Lucia P, Lang R, et al. Inhibition of IL-12 production by 1,25-dihydroxyvitamin D3. Involvement of NF-kappaB downregulation in transcriptional repression of the p40 gene. J Clin Invest1998 Jan 01;101(1):252-62.

14. Cantorna MT, Humpal-Winter J, DeLuca HF. In vivo upregulation of interleukin-4 is one mechanism underlying the immunoregulatory effects of 1,25-dihydroxyvitamin D(3). Arch Biochem Biophys2000 May 01;377(1):135-8.

15. Sloka S, Silva C, Wang J, Yong VW. Predominance of Th2 polarization by vitamin D through a STAT6-dependent mechanism. J Neuroinflammation2011 May 24;8:56.

16. Bansal AS, Henriquez F, Sumar N, Patel S. T helper cell subsets in arthritis and the benefits of immunomodulation by $1,25(\mathrm{OH})(2)$ vitamin $\mathrm{D}$. Rheumato Int2012 Apr;32(4):845-52.

17. Scichilone N, Pedone C, Battaglia S, Sorino C, Bellia V. Diagnosis and management of asthma in the elderly. Eur J Intern Med2014 Apr;25(4):336-42.

18. Battaglia S, Benfante A, Scichilone N. Asthma in the older adult: presentation, considerations and clinical management. Expert Rev Clin Immunol2015;11(12):1297-308.

19. Al-Alawi M, Hassan T, Chotirmall SH. Advances in the diagnosis and management of asthma in older adults. Am J Med2014 May;127(5):370-8.

20. Arjona N. Near-fatal asthma in the elderly. Dimens Crit Care Nurs2015 JanFeb;34(1):26-32

21. Bom AT, Pinto AM. Allergic respiratory diseases in the elderly. Respir Med2009 Nov;103(11):1614-22.

22. BTS. 2016 British Thoracic Society (BTS)/ Scottish Intercollegiate Guidelines Network (SIGN) guideline no.153 - British guideline on the management of asthma- A national clinical guideline: https://www.brit-thoracic.org. uk/document-library / clinical-information/asthma / btssign-asthmaguideline-2016. Last accessed 7th Aug, 2017

23. National Institute for Health and Care Excellence (NICE). Asthma: diagnosis and monitoring of asthma in adults, children and young people, London: NICE; 2015. https:// www.nice.org.uk/guidance/gid-cgwave0640/ documents / draft-guideline Last accessed 7th Aug, 2017

24. Eysink PE, ter Riet G, Aalberse RC, van Aalderen WM, Roos CM, van der Zee JS, et al. Accuracy of specific IgE in the prediction of asthma: development of a scoring formula for general practice. Br J Gen Pract2005 Feb;55(511):125-31.

25. Time and Date server, 2016: https://www.timeanddate.com/sun/uk/ maidstone. Last accessed 7th Aug 2017

26. Midlands Asthma and Allergy Research Association, (MAARA2). 2016; Available from: http:/ / www.maara.org/2013-08-19-06-21-06/spore-calendar Last accessed 7th Aug 2017

27. Midlands Asthma and Allergy Research Association, (MAARA). http:// wwwmaaraorg/2013-08-19-06-21-06/ pollen-calendar http: / / www.maara. 
org/2013-08-19-06-21-06/ pollen-calendar Last accessed 7th Aug 2017

28. ICH Harmonised Tripartite Guideline: Guideline for Good Clinical Practice E6(R1). ICH working group; 1996 http:/ / www.ich.org/fileadmin/Public Web_Site/ICH_Products/Guidelines/Efficacy / E6/E6_R1_Guideline.pdf Last accessed 7th Aug 2017

29. Declaration of Helsinki - Ethical Principles for Medical Research Involving Human Subjects. Helsinki, Finland: World Medical Association; 1964 [updated 2013]; https:/ / www.wma.net/policies-post/wma-declaration-ofhelsinki-ethical-principles-for-medical-research-involving-human-subjects / Last accessed 7th Aug 2017

30. British National Formulary. British Medical Association and Royal Pharmaceutical Society of Great Britain, 2017.

31. Kent Census- 2011 Census population: Age and gender profile (unrounded). Maidstone: Kent County Council; 2011 https://www.kent.gov.uk/_data/ assets / pdf_file / 0005 /12479/2011-Census-population-age-and-genderprofile.pdf Last accessed 7th Aug 2017

32. Sahay M, Sahay R. Rickets vitamin D deficiency and dependency. Indian Journal of Endocrinology and Metabolism 2012 Mar-Apr;16(2):164-76.

33. Tsiaras WG, Weinstock MA. Ultraviolet irradiation and oral ingestion as sources of optimal vitamin D. J Am Acad Dermatol 2010 Jun;62(6):935-6.

34. Diffey BL. Modelling the seasonal variation of vitamin D due to sun exposure. Br J Dermatol2010 Jun;162(6):1342-8.

35. Lawson DE, Paul AA, Black AE, Cole TJ, Mandal AR, Davie M. Relative contributions of diet and sunlight to vitamin D state in the elderly. Br Med J1979 Aug 4;2(6185):303-5.

36. Pacini L, Ceraolo MG, Venuti A, Melita G, Hasan UA, Accardi R, et al. UV Radiation Activates Toll-Like Receptor 9 Expression in Primary Human Keratinocytes, an Event Inhibited by Human Papillomavirus 38 E6 and E7 Oncoproteins. J Virol2017 Oct 01;91(19).

37. Bener A, Ehlayel MS, Tulic MK, Hamid Q. Vitamin D deficiency as a strong predictor of asthma in children. Int Arch Allergy Immunol2012;157(2):168-75.
38. Ali NS, Nanji K. A Review on the Role of Vitamin D in Asthma. Cureus2017 May 29;9(5):e1288.

39. Jat KR, Khairwa A. Vitamin D and asthma in children: A systematic review and meta-analysis of observational studies. Lung India2017 JulAug;34(4):355-63.

40. McKean MC, Leech M, Lambert PC, Hewitt C, Myint S, Silverman M. A model of viral wheeze in nonasthmatic adults: symptoms and physiology. Eur Respir J2001 Jul;18(1):23-32.

41. Strina A, Barreto ML, Cooper PJ, Rodrigues LC. Risk factors for non-atopic asthma/wheeze in children and adolescents: a systematic review. Emerg Themes Epidemiol2014;11:5.

42. Walker S, Monteil M, Phelan K, Lasserson TJ, Walters EH. Anti-IgE for chronic asthma in adults and children. Cochrane Database Syst Rev2006 Apr 19(2):CD003559.

43. Green AC, Olsen CM. Cutaneous squamous cell carcinoma: an epidemiological review. Br J Dermatol2017 Feb 16. doi: 10.1111/bjd.15324. [Epub ahead of print]

44. Liu J, Pang Z, Wang G, Guan X, Fang K, Wang Z, et al. Advanced Role of Neutrophils in Common Respiratory Diseases. J Immunol Res 2017;:6710278. doi: 10.1155/2017/6710278. Epub 2017 May 15

45. Institute of Medicine (US) Committee to Review Dietary Reference Intakes for Vitamin D and Calcium; Ross AC, Taylor CL, Yaktine AL, et al., editors. Dietary Reference Intakes for Calcium and Vitamin D. Washington (DC): National Academies Press (US); 2011. Available from: https://www.ncbi. nlm.nih.gov/books/NBK56070/ Last accessed 7th Aug 2017

46. National Osteoporosis Society, 2013. Vitamin D and bone health: a practical clinical guideline for patient management. Available at: https://nos.org.uk/ media/2073/vitamin-d-and-bone-health-adults.pdf last accessed 7th Aug 2017. 